\title{
Educación filosófica y ciudadanía: La vocación política de los estudios generales ${ }^{1}$
}

\section{Philosophical education and citizenship: The political vocation of general studies}

Recibido: 29 de septiembre de 2021 | Aprobado: 29 de noviembre de 2021

\section{Resumen}

Si bien es cierto que no existen las democracias perfectas, sí podemos afirmar que existen las democracias más o menos democratizadas. Sin embargo, queda por descubrir el modo de democratizar las democracias. En este ensayo, apoyados en un

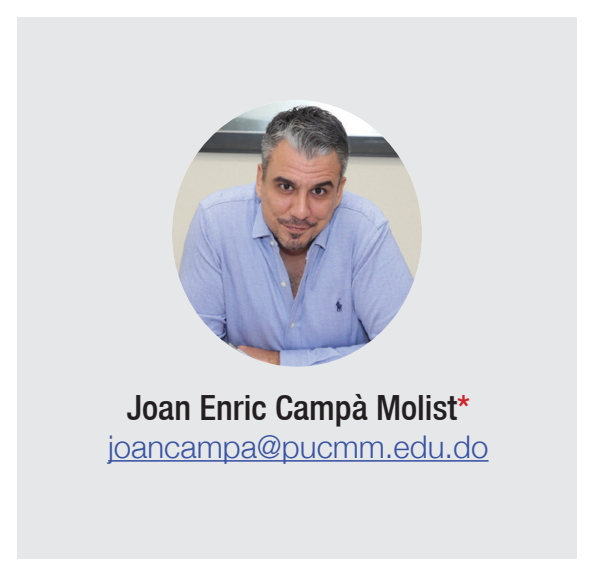
análisis comparativo entre el concepto ciudadanía y educación filosófica (o educación en filosofía), se plantean dos hipótesis relativas al carácter democratizador de la educación y al papel que deben cumplir los Estudios Generales desde su dimensión política. Como conclusión, y respaldado por autores como Robert Alan Dahl y Carlos S. Nino, especialmente, se expondrá el lazo transdisciplinar que aúna la educación filosófica, el estatus de ciudadanía, los índices de desarrollo humano y justicia social.

Palabras clave: Educación filosófica, democratización, ciudadanía, democracia, Estudios Generales

\begin{abstract}
Although it is true that there are no perfect democracies, we can assert there are democracies more democratized than others. However, how to democratize democracies remains to be discovered. In this article, supported by a comparative analysis between the concept of citizenship and philosophical education (or education in philosophy), two hypotheses are proposed regarding the democratizing nature of education and the role that General Studies must fulfill from its political dimension. In conclusion -and supported by authors such as Robert Alan Dahl and Carlos S. Nino, especially- the transdisciplinary bond that unites philosophical education, citizenship status, human development indices and social justice will be exposed.
\end{abstract}

Keywords: Philosophical education, democratization, citizenship, democracy, General Studies.

1 Ponencia presentada en junio de 2021 en el XII Simposio Internacional de Estudios Generales (modalidad virtual). Pontificia Universidad Católica Madre y Maestra (PUCMM), República Dominicana, y Red Internacional de Estudios Generales (RIDEG).

* Doctor en Derechos Humanos y Filosofía Política (UAB). Director y profesor del Departamento de Estudios Generales, PUCMM-CSD. Para contactar al autor: joancampa@pucmm.edu.do

ISSN (en línea): 1814-4152 / Sitio web: http://cuaderno.pucmm.edu.do

CÓmO CITAR: Campà Molist, J. (2022). Educación filosófica y ciudadanía: la vocación política de los Estudios Generales. Cuaderno de Pedagogía Universitaria, 19 (37), 31-35. 


\section{Introducción}

Actualmente, estamos abrigados por una terrible pandemia de carácter viral, y, gracias al desarrollo científico, disponemos de una vacuna para combatir la enfermedad. Quizá no tan democráticamente como desearíamos, pero disponemos de ella. No obstante, para la pandemia que obstaculiza el desarrollo social, para la pandemia que impide una gobernabilidad eficiente, para la pandemia que incentiva a la desigualdad, lamentablemente, no tenemos una vacuna. Parece que convivimos bajo un contrato social que no funciona, el Estado, ha quedado peligrosamente enfermo y se requiere, urgentemente, más sociedad con carácter de ciudadanía. La primera línea de defensa para el desarrollo debe ser, cómo no, una defensa intelectual.

Este ensayo tiene por objetivo exponer un vínculo transdisciplinar que tiene como fin despertar y avivar, positivamente, los índices de desarrollo humano y justicia social. Una relación entre la educación filosófica, o educación en Filosofía, la democracia y el desarrollo social conforman una ecuación transdisciplinar que despierta en los Estudios Generales como la vertiente más política de un primer ciclo universitario y se caracteriza por procurar el cultivo de seres humanos responsables de sí mismos y de su entorno.

No obstante, e iniciando con la cuestión que el filósofo francés Jean-Luc Nancy planteó en su texto "Après le sujet qui vient" (Nancy, 1989): ¿qué viene después del sujeto? Étienne Balibar (Balibar, 2013) responde muy convencido: después del sujeto, viene el ciudadano, una categoría indispensable para la praxis política y para la democratización constante de la democracia. Considerando que las articulaciones de la democracia están plenamente relacionadas con las acciones de la ciudadanía, y estas acciones a las decisiones de esta, la educación y preparación del ciudadano se convierte en uno de los pilares fundamentales de aquello que llamamos justicia democrática. Sin embargo, surgen varias interrogantes ante tal ecuación que es menester responder sin miedo, como: ¿Cuál es el elixir del que debe alimentarse una auténtica educación democrática y democratizadora? ¿Qué papel cumplen los estudios Generales en la democratización de la democracia?
Para dar respuesta a dichas cuestiones, conviene abordar conceptos clave como "Educación filosófica", "ciudadanía”, "democracia” y "Estudios Generales". Iniciemos.

2. El carácter filosófico de la educación democrática: un paso hacia "lo político"

Bien sabido es que en la historia de la humanidad han surgido incontables modos de enseñanza y sistemas educativos, pero, si nucleamos la ecuación con el concepto "emancipación", es conveniente reducir la educación a dos tipos muy generales: la educación que uno recibe de los demás y la educación que uno recibe de sí mismo. Hoy día, educar para la emancipación no debe darnos miedo, sino todo lo contrario: la emancipación cultivada en la ciudadanía debe entenderse como la pieza que propicia dinamismo a la democracia y sirve de alimento para su constante democratización. Una democracia ideal, considerada como un organismo vivo que se desarrolla en la actualización y el dinamismo, requiere de la presencia y ejercicio de ciudadanos activos y libres en cuanto a pensamiento se refiere.

El Republicanismo como modelo de teoría política explica la actualidad de la educación para la ciudadanía, tratándose de una Filosofía política que procura una redefinición de todo. Es la apuesta de aquellos que creen que es posible pensar, de un modo distinto, "lo político" y "lo educativo". Si se considera que "lo político" no puede estar relacionado únicamente con las cuestiones relativas al poder, es decir, que "lo político" engloba todas las dimensiones de la vida, la alternativa a la educación cívica será la Filosofía, y así, el filosofar será la expresión y acción política por excelencia. Si no enseñamos a filosofar al ciudadano, no habrá política, y si no hay política, nos quedamos sin democracia. En tal orden, y respondiendo a la cuestión inicial al respecto del elixir que debe brindarse a la educación para la ciudadanía, nos encontramos con una Filosofía salvíica en cuanto a emancipación se refiere.

Es muy común entender la Filosofía como una actividad alejada, extraña y ajena a la cotidianidad. Incluso, se ha llegado a percibir la Filosofía como la principal enemiga de las religiones. Se percibe como un ejercicio que sólo compete a intelectuales 
divinizados y a aburridos soñadores que distraen y confunden con sus disertaciones. Son, pues, un cúmulo de concepciones altamente nocivas para la democracia al estar tan arraigadas a la población. Estas concepciones, unas elitistas y otras escépticas, han servido para apartar a la Filosofía y convertirla en algo ajeno a nuestra naturaleza humana, y, en tal sentido, la recuperación de la Filosofía para la ciudadanía resulta ser el objetivo primero de una educación democrática orientada a la formación ciudadana.

Parece, pues, que la alternativa recae en el papel de la Filosofía en la educación, pero, cabe preguntarnos: ¿qué tipo de Filosofía debe enseñarse? Tal como afirmó Feuerbach, es menester recuperar una Filosofía que aborde los problemas de la humanidad: "Una cosa es la Filosofía que debe su existencia solamente a la indigencia filosófica (...), y muy distintamente, una Filosofía que corresponde o coincide con la indigencia de la humanidad" (Feuerbach, 1984). Esta afirmación puede coincidir con el talante socrático de tantos maestros que son capaces de despertar en los discentes el desazón y ansiedad que la misma existencia comporta. Aquello que Kant nombró, stricto sensu, "filosofar".

Siguiendo la ruta del filósofo alemán, nos encontramos con la atormentadora cuestión ¿qué debo hacer?: la cuestión que origina la concepción moderna de ciudadano desde el plano ético. Con el andar del tiempo, florecen nuevas modalidades contemporáneas de pensar la ciudadanía, especialmente desde Jean Marie Guyau y Georg Simmel, los cuales presentan de manera opuesta la ley universal y el sentido individualista de la acción moral. Con sus postulados, la educación cívica ha sufrido una crisis al no poder abordar efectivamente el concepto "deber", una razón añadida a la importancia de la educación y actividad filosófica entendida como una actividad racional, y por lo tanto humana, que tiende a la universalización. Sin embargo, esta cuestión choca frontalmente con la desaparición de la educación en Filosofía de los currículums escolares y universitarios: parece que el progreso moral obstaculiza al progreso material que impera en los sistemas educativos-económicos. Con el bullicio explicado, la demanda de respuestas por parte de la ciudadanía no cesa e incrementa.
Centrándonos en el ciudadano, a diferencia de otras figuras, es aquel que ejerce la libertad y el ejercicio racional de la acción política. Este no tiene que reivindicarla, pues ya la posee: es la figura que se encuentra más cerca de la ética y la política, y, por ello mismo, requiere beber del elixir de la emancipación y la autonomía intelectual para culminar debidamente con sus objetivos como ciudadano. En otras palabras, podemos determinar que para una ciudadanía efectiva se requiere, cómo no, la educación filosófica orientada a la emancipación y autonomía intelectual del discente.

\section{Democracia y ciudadanía: un paso hacia} "lo social"

Si bien el pensamiento antidemocrático que Platón expone en La República ha sido difícilmente superado, mediante fuertes cefaleas e insomnios traicioneros, nos encontramos en un período teórico en el que brotan esperanzas para la democracia. Personalidades como Robert Alan Dahl o Carlos Santiago Nino nos ofrecen alternativas para repensar lo democrático y lo político. Empecemos por el primero.

Dahl (Dahl, 2012), consciente de la difícil tarea de alcanzar una democracia ideal, propone cinco principios esperanzadores para, como mínimo, lograr una democracia equilibrada alejada de utopías, a saber: la participación efectiva, la igualdad del voto en la fase electoral, la comprensión informada, el control de la agenda y la inclusividad. A pesar de tratarse de cinco únicos principios, las dificultades que arrastran son de magna relevancia y competen, en esencia, a la esfera educativa del Estado y al compromiso resultante del ciudadano.

Con relación al primer principio (participación efectiva), exige que los ciudadanos sepan practicar la igualdad entre ellos formalizando sus preferencias y cuestiones en la agenda pública, además de ofrecer razones racionales a favor de un resultado $u$ otro. Con relación al segundo principio (igualdad de voto en la fase electoral) exige considerar el valor de cada voto x1, y ello requiere que cada punto de vista sea tomado en cuenta, y se respete, por parte de la propia ciudadanía. El tercer principio (comprensión informada) requiere de una preparación formada por parte de los ciudadanos, es decir, que cada uno pueda disfrutar de oportunidades amplias, 
diversas y equitativas para conocer y afirmar la decisión más adecuada para el bien común. El cuarto principio (control de la agenda), necesita que la ciudadanía (Demos) tenga la oportunidad de decidir cuáles son los temas políticos más urgentes y necesarios para someter a la deliberación. El quinto principio (inclusividad) es el encargado de ofrecer equitatividad a todo el plano ciudadano y legitimidad a sus intereses durante el proceso político.

Tanto el primer principio como el tercero y el cuarto, y siguiendo el hilo del apartado anterior, denotan una necesidad de considerar la emancipación como una pieza fundamental de la educación para el efectivo ejercicio de lo político, esto es, la ciudadanía entendida como una práctica y ejercicio vital para la democratización de la democracia, no como un mero estatus jurídico. En tal orden, nacen dos necesarios vínculos entre el ejercicio de la ciudadanía y la formación/educación filosófica desde la emancipación y autonomía intelectual: el aspecto salvífico para la concientización de los dolores del mundo y la sensibilidad de uno mismo para con el resto de la humanidad.

Desde el pensamiento de Carlos Santiago Nino, y de un modo ligeramente distinto, nos encontramos con una importante distinción de conceptos en lo que él mismo se refiere como discurso moral. En la parcela social del Estado, es decir, el ámbito de la ciudadanía, podemos encontrarnos con dos tipos de moralidad, principalmente: la moral social y la moral crítica (Nino, 1991). La primera se refiere a aquellos principios morales que, además de estar enraizados en el seno de la sociedad, se presentan como criterios infalibles; son principios aparentemente inapelables que la sociedad obedece por inercia y sin ningún tipo de cuestionamiento y crítica. Se trataría de la obediencia en el más puro sentido de la palabra. Por otro lado, y de un modo menos popularizado, nos encontramos con la moral crítica, una moral que, lejos de someterse a los estándares establecidos, es y piensa por sí misma desde la emancipación y la autonomía de quien la ejerce. Se trata de una moral que duda, que cuestiona, que practica con criticidad la libertad intelectual y moral con el fin de encontrar una correspondencia con lo justo. Es, pues, un tipo de moral que propicia el desarrollo humano de la ciudadanía y que auspicia la justicia social.

\section{Conclusión}

La educación propia de los Estudios Generales puede parecer un oxímoron, pues tanto en sus planteamientos como en sus resultados ofrece luz, pero también oscuridad. Permítanme explicarlo. Menciono luz por el carácter revelador de conocimiento y cultura de la educación general, claro está, desde una óptica transdisciplinar apoyada en la investigación, la lectura y la escritura. Pero también menciono oscuridad por el carácter mayéutico/socrático de su enseñanza, es decir, por ser descubridora de verdades (en plural) mediante el debate y la argumentación crítica, no de una Verdad (en singular) mediante un discurso infalible.

talante filosófico que nuclea los Estudios Generales es el aporte más delicado y transgresor de tal educación, pues la cuestión filosófica obliga a caminar a oscuras, a ciegas, por el sendero del conocimiento. La duda filosófica es el ardor del aprendizaje, es la soledad del intelecto ante un mundo rebosado de sentencias que propician la negación de uno mismo, es decir, la anulación del pensamiento y criterio propio. Sin este componente, educar para generar o incentivar el sentido crítico en nuestros estudiantes se convierte en una pérdida de tiempo, en papel mojado, en humo ventilado.

El autoconocimiento o conocimiento sobre uno mismo, considerado como un imperativo socrático, es aquel que nos conduce a manejar las virtudes individuales de una manera equilibrada y consciente (Barni, 1992). Estas virtudes son indispensables para la constitución del ciudadano y una resultante sociedad democrática orientada hacia "el otro". Sin una buena disposición hacia uno mismo, difícilmente podremos actuar efectivamente como ciudadanos ante el otro, esto es, el resto de la ciudadanía, primero, y la humanidad, como consecuencia. Para el mismo autor, todas las virtudes quedan agrupadas en tres grandes bloques: cultura de la humanidad, respeto a la dignidad humana y el perfeccionamiento moral, y este último bloque es el que se familiariza directamente con la idea de ciudadanía activa y comprometida: el punto de partida para la construcción de la ciudadanía ideal y para la democratización de la democracia.

Es evidente que el papel de la educación general nucleada en el pensamiento filosófico se convierte 
en la protagonista de los tres bloques: en el primero, al respecto de la conciencia de pertenencia y necesario cuidado de la humanidad, en el segundo, respecto al pensar la condición humana desde el denominador común que nos une (esto es la dignidad inherente a nuestra naturaleza), y en el tercero, al respecto de preguntarnos ¿cómo debemos actuar desde nosotros mismos para con el resto de ciudadanos después de repensar lo sabido?

Por lo mencionado, el presente ensayo procuró desvelar el protagonismo de la Filosofía en la Educación General entendida como la educación que requiere la ciudadanía, la cual tiene como fin democratizar el sistema político que más efectividad ha mostrado en la historia de la humanidad: la democracia. Nuestro papel en este escenario es, pues, el de libertadores de conciencias que, mediante el canal de la duda y los saberes, generan buscadores de certezas animados por la curiosidad y la responsabilidad por el otro. No es una tarea fácil, pero tampoco imposible, pues somos conscientes, aquí y ahora, de que la emancipación intelectual y el sentido de ciudadanía despertado mediante el pensar filosófico son la condición de posibilidad de la democracia y el desarrollo social, jamás a la inversa.

\section{Referencias bibliográficas}

Balibar, E. (2013). Ciudadano sujeto. Vol. 1: El sujeto ciudadano. Prometeo Libros.

Barni, J. (1992). La morale dans la Démocratie suivi du Manuel Républicain. Kimé.

Dahl, R. A. (2012). La Democracia. Editorial Ariel.

Feuerbach, L. (1984). Manisfestos Antropològics. Editorial Laia.

Nancy, J. L. (1989). "Présentation”, en Cahier Confrontation "Après le sujet qui vient", N²0.

Nino, C. S. (1991). Ética y Derechos Humanos. Oxford University. 